\title{
Anti-TNF antibody-induced psoriasiform skin lesions in patients with inflammatory bowel disease are characterised by interferon- $\gamma$-expressing Th1 cells and IL-17A/IL-22-expressing Th17 cells and respond to anti-IL-12/LL-23 antibody treatment
}

\author{
Cornelia Tillack, ${ }^{1}$ Laura Maximiliane Ehmann, ${ }^{2}$ Matthias Friedrich, ${ }^{1,3}$ \\ Rüdiger P Laubender, ${ }^{4}$ Pavol Papay, ${ }_{1}^{5}$ Harald Vogelsang, ${ }_{1}{ }^{5}$ Johannes Stallhofer, ${ }^{1}$ \\ Florian Beigel, ${ }^{1}$ Andrea Bedynek, ${ }^{6}$ Martin Wetzke, ${ }^{1,7}$ Harald Maier, ${ }^{8}$ Maria Koburger, ${ }^{1}$ \\ Johanna Wagner, ${ }^{1,3}$ Jürgen Glas, ${ }^{1,3,9}$ Julia Diegelmann, ${ }^{1,3}$ Sarah Koglin, ${ }^{2}$ \\ Yvonne Dombrowski, ${ }^{2,10}$ Jürgen Schauber, ${ }^{2}$ Andreas Wollenberg, ${ }^{2}$ Stephan Brand ${ }^{1}$
}

\begin{abstract}
- Additional figures, tables and material are published online (see text for more details). To view please visit the journal online (http://dx. doi.org/10.1136/gutjnl-2012302853).
\end{abstract}

For numbered affiliations see end of article.

\section{Correspondence to Prof Dr Stephan Brand, Department of Medicine II, University-Hospital \\ Munich-Grosshadern, Ludwig Maximilians University Munich, Munich D-81377, Germany; stephan.brand@med.uni- muenchen.de}

This article is published in full online. To view, please visit http://dx.doi.org/10.1136/ gutjnl-2012-302853.

Received 4 May 2012 Revised 21 January 2013 Accepted 7 February 2013 Published Online First 6 March 2013

\section{Linked}

- http://dx.doi.org/10.1136/ gutjnl-2013-304683

- http://dx.doi.org/10.1136/ gutjnl-2013-305478

\footnotetext{
To cite: Tillack $C$ Ehmann LM, Friedrich $\mathrm{M}$, et al. Gut 2014;63: 567-577.
}

\section{ABSTRACT}

Background We analysed incidence, predictors, histological features and specific treatment options of anti-tumour necrosis factor $\alpha$ (TNF- $\alpha$ ) antibody-induced psoriasiform skin lesions in patients with inflammatory bowel diseases (IBD).

Design Patients with IBD were prospectively screened for anti-TNF-induced psoriasiform skin lesions. Patients were genotyped for IL23R and IL $12 B$ variants. Skin lesions were examined for infiltrating Th1 and Th17 cells. Patients with severe lesions were treated with the anti-interleukin (IL)-12/IL-23 p40 antibody ustekinumab.

Results Among 434 anti-TNF-treated patients with IBD, 21 (4.8\%) developed psoriasiform skin lesions. Multiple logistic regression revealed smoking ( $p=0.007$; OR $4.24,95 \% \mathrm{Cl} 1.55$ to 13.60$)$ and an increased body mass index ( $p=0.029 ;$ OR $1.12,95 \% \mathrm{Cl} 1.01$ to 1.24 ) as main predictors for these lesions. Nine patients with Crohn's disease and with severe psoriasiform lesions and/or anti-TNF antibody-induced alopecia were successfully treated with the anti-p40-IL-12/IL-23 antibody ustekinumab (response rate 100\%). Skin lesions were histologically characterised by infiltrates of IL-17A/IL-22-secreting T helper 17 (Th17) cells and interferon (IFN)- $\gamma$-secreting Th1 cells and IFN- $\alpha$ expressing cells. IL-17A expression was significantly stronger in patients requiring ustekinumab than in patients responding to topical therapy ( $p=0.001$ ). IL23R genotyping suggests disease-modifying effects of rs11209026 (p.Arg381GIn) and rs7530511

(p.Leu310Pro) in patients requiring ustekinumab. Conclusions New onset psoriasiform skin lesions develop in nearly $5 \%$ of anti-TNF-treated patients with IBD. We identified smoking as a main risk factor for developing these lesions. Anti-TNF-induced psoriasiform skin lesions are characterised by Th17 and Th1 cell infiltrates. The number of IL-17A-expressing T cells correlates with the severity of skin lesions. Anti-IL-12/IL23 antibody therapy is a highly effective therapy for these lesions.

\section{Significance of this study}

What is already known about this subject?

- Anti-tumour necrosis factor (TNF) antibodies may induce psoriasiform skin lesions but predictors, histological features and specific treatment options of these lesions are largely unknown.

\section{What are the new findings?}

- We performed the first prospective study on anti-TNF-induced psoriasiform skin lesions allowing for calculation of an incidence rate for these lesions which is almost $5 \%$ in anti-TNF-treated patients with inflammatory bowel diseases (IBD), therefore identifying these lesions as a relevant side effect of anti-TNF therapy. In addition, we identified smoking as the main risk factor for these lesions.

- Anti-TNF-induced psoriasiform skin lesions are characterised by infiltrates of interleukin (IL)-17A/IL-22-expressing $T$ helper (Th17) cells and interferon (IFN)- $\gamma$-expressing Th1 cells, and the severity of skin lesions correlates with the density of Th17 cell infiltrates.

- This is the first study in patients with anti-TNF-induced psoriasiform skin lesions and severe anti-TNF-induced alopecia that shows a very high treatment response to the anti-IL-12/ IL-23 antibody ustekinumab which inhibits Th1 and Th17 cell differentiation.

- We provide a detailed genotype analysis of IBDand psoriasis-associated IL23R, IL23, IL12B gene variants in patients with anti-TNF-induced skin lesions, suggesting disease-modifying effects of rs11209026 (p.Arg381Gln) and rs7530511 ( $p$. Leu310Pro) in patients with severe lesions requiring ustekinumab. 


\section{Significance of this study}

\section{How might it impact on clinical practice in the foreseeable future? \\ - Our study suggests that the anti-IL-12/LL-23 antibody ustekinumab, which targets Th1 and Th17 cells, is highly effective and the first disease-specific treatment option in patients with severe anti-TNF-induced psoriasiform skin lesions and anti-TNF-induced alopecia.}

\section{INTRODUCTION}

Anti-tumour necrosis factor $\alpha$ (TNF- $\alpha)$ antibodies such as infliximab and adalimumab are used for the treatment of moderate to severe Crohn's disease (CD) and ulcerative colitis (UC). Although anti-TNF antibodies are regarded as safe agents, ${ }^{1}$ potential side effects include allergic reactions, opportunistic infections including reactivation of tuberculosis, and an increased risk of lymphoma, particularly when given simultaneously with thiopurines. ${ }^{23}$ In addition, recent studies indicate that anti-TNF antibodies may cause psoriasiform skin lesions in a subgroup of anti-TNF-treated patients with inflammatory bowel disease (IBD). ${ }^{45}$ This side effect seems to be paradox given that TNF- $\alpha$ plays a key role in the pathogenesis of psoriasis and anti-TNF inhibitors are used for the treatment of severe psoriasis. Furthermore, the pathogenesis of this side effect is not well understood and only very few larger case series of anti-TNF antibody-treated patients with IBD have been published. ${ }^{4}$ In addition, there is currently no specific treatment available for these skin lesions and treatment is mostly limited to topical steroid therapy or termination of anti-TNF therapy in severe cases.

Although the detailed pathogenesis of IBD is not completely understood, it is assumed that CD and UC develop in a genetically susceptible host and are caused by an exaggerated immune response against the intestinal bacterial flora. $\mathrm{CD}$ is characterised by increased $\mathrm{T}$ helper 1 (Th1) and Th17 cytokine expression, while UC shows a modified Th2 cytokine response and an increased expression of Th17 cytokines. ${ }^{7-11}$ Similarly, there is an enhanced expression of Th17 cytokines such interleukin (IL)-17A and IL-22 in skin lesions of patients with psoriasis. ${ }^{12-14}$ Genome-wide association studies identified single nucleotide polymorphisms (SNPs) in the IL23R and IL12B gene as susceptibility variants for $\mathrm{CD}$, UC and psoriasis. ${ }^{15-19}$ Moreover, anti-IL-12/IL-23 therapy has been approved for the treatment of psoriasis and recent studies showed some efficacy in the treatment of $\mathrm{CD} .^{20-23}$

Given that the epidemiology and pathogenesis of anti-TNF antibody-induced psoriasiform skin lesions are largely unknown, we aimed to characterise the incidence, clinical manifestations, histological characteristics, associated risk factors and treatment modalities of these lesions in a well characterised cohort of patients with IBD. Considering the key role of IL- 12 and IL-23 in the pathogenesis of $\mathrm{CD}$ and psoriasis, we performed the first study using the anti-IL-12/IL-23 p40 antibody ustekinumab in severe cases of anti-TNF-induced psoriasiform skin lesions. Moreover, this study contains a detailed genetic analysis of the role of IBD- and psoriasis-associated $I L 23 R$ and $I L 12 B$ gene variants regarding the development of anti-TNF-induced psoriasiform skin lesions.

\section{METHODS}

\section{Study population}

Patients treated with anti-TNF antibodies (infliximab and/or adalimumab) in the IBD centre of the University Hospital
Munich-Grosshadern from January 2010 to September 2011 were included in this study. The study population included $\mathrm{n}=434$ patients with IBD of Caucasian origin (patients with CD: $n=331$; patients with UC: $n=103$ ). Written, informed consent was obtained from all patients before IL12B, IL23R and IL23A genotyping and before treatment with anti-TNF antibodies and/or ustekinumab. The Ethics committee of the Medical Faculty of the Ludwig Maximilians University Munich approved the genotyping and the study adhered to the ethical principles for medical research involving human subjects of the Helsinki Declaration. We collected clinical disease characteristics from patients' charts, a detailed written questionnaire, and an interview at the time of enrolment. The diagnosis of $\mathrm{CD}$ or $\mathrm{UC}$ was made using clinical, endoscopic, histopathological and radiological criteria. ${ }^{24}$

\section{Dermatological evaluation, skin biopsies and immunohistochemical staining}

All patients with IBD with skin lesions were examined by an independent, experienced, board-certified dermatologist. The skin lesions were classified into four major categories based on their clinical appearance and the histological examination: palmoplantar psoriasis, pustular palmoplantar psoriasis (type Barber-Königsbeck), guttate psoriasis, and psoriasis of the scalp including psoriasis-associated alopecia. Diagnostic punch biopsies were performed for histological examination and immunohistochemical staining in severely affected patients. Written consent was obtained for all invasive procedures. Details of the immunohistochemical staining procedure are given in the online supplementary information. In addition to $\mathrm{H} \& \mathrm{E}$ staining, immunhistochemical staining with antibodies against IL-17A, IL-22, interferon (IFN)- $\gamma$, IFN- $\alpha$, TNF- $\alpha$, CD3 and CD4 was performed. Semiquantitative evaluation of the immunohistochemical stainings was performed using the following grading: no staining (0), weak positive staining (1), moderate positive staining (2) and strong positive staining (3) for the respective antibody.

\section{Treatment of psoriasiform skin lesions with the anti-IL-12/IL-23 antibody ustekinumab}

Following consultation with an experienced, board-certified dermatologist, patients with severe psoriasiform skin lesions not improving under topical therapy requiring cessation of anti-TNF treatment were switched to the anti-IL-12/IL-23 antibody ustekinumab (Stelara), which is approved for moderate to severe plaque psoriasis in Europe, the USA and Canada. Before treatment, all patients were informed that ustekinumab is currently approved only for psoriasis and that it has been used for treatment of $\mathrm{CD}$ in clinical trials only. ${ }^{20-23}$ Ustekinumab was given at week 0 and 4 (45 mg each subcutaneously) and every 12 weeks thereafter, using the treatment protocol for psoriasis, unless stated otherwise. All patients weighed less than $100 \mathrm{~kg}$ (for patients $>100 \mathrm{~kg}$ a dose increase to $90 \mathrm{mg}$ ustekinumab subcutaneously has been recommended).

\section{DNA extraction and genotyping of the IL12B, IL23R and IL23A variants}

A total of 17 SNPs of IBD- and psoriasis-associated IL23R, IL12B and IL23A gene variants (rs1004819, rs7517847, rs10489629, rs2201841, rs11465804, rs11209026, rs1343151, rs10889677, rs11209032, rs1495965, rs12131065, rs7530511, rs3212227, rs6887695, rs2082412, rs10045431, rs2066808) were genotyped by PCR and melting curve analysis using a pair of fluorescence resonance energy transfer probes in a LightCycler 480 Instrument (Roche Diagnostics, Mannheim, 
Germany). Details of the genotyping procedure were described in detail in previous publications ${ }^{16}{ }^{25-28}$ and are given in the online supplementary information and supplementary table S1.

\section{Statistical analyses}

For comparison between categorical variables, Fisher's exact test or $\chi^{2}$ test was used when appropriate. Each genetic marker was tested for Hardy-Weinberg equilibrium in the control population. Single-marker allelic tests were performed with Pearson's $\chi^{2}$ test. Student's t test was applied for quantitative variables. For modelling the dichotomous outcome 'psoriasiform skin lesion', we used the logistic regression model. First, for each predictor of a set of potential predictors (shown in table 1), the OR, the corresponding 95\% $\mathrm{CI}$ and the $\mathrm{p}$ value resulting from the Wald test were estimated. Second, a multiple logistic regression model was built with predictors selected from the set of candidate predictors using a backward elimination algorithm with complete cases and the variable selection level for all predictors was set to 0.05. All tests were two tailed, considering $\mathrm{p}$ values $<0.05$ as statistically significant. Data were evaluated by using the SPSS V.13.0 software and R 2.13.2. (http://cran.r-project.org).

\section{RESULTS}

\section{Incidence and predictors of psoriasiform skin lesions} in patients with IBD

From January 2010 to September 2011, 434 patients with IBD were treated with anti-TNF antibodies infliximab $(n=416)$ and/or adalimumab $(n=141)$ in our IBD centre. Of these 434 patients, $\mathrm{n}=21(4.8 \%)$ developed psoriasiform skin lesions; 19 of these 21 patients $(90.5 \%)$ had CD and $2(9.5 \%)$ had UC. In contrast, there were 312 patients with $\mathrm{CD}$ and 101 patients with UC in the anti-TNF-treated patient group without psoriasiform skin lesions $(p=0.14$ for comparing CD prevalences in the subgroups with and without skin lesions; table 1). Of the patients with skin lesions,
$11(52.4 \%)$ were women and 10 (47.6\%) were men. Patient characteristics, clinical and histological features of the skin disorders are listed in table 2 (online only). Comparing anti-TNF-treated patients with IBD with and without skin lesions, we found significant differences in the smoking status, body mass index (BMI) and IBD duration (table 1). We confirmed these three disease characteristics as predictors of anti-TNF-induced psoriasiform skin lesions in multiple logistic regression analysis. Multiple logistic regression showed smoking (defined as active smoking or a history of smoking; $\mathrm{p}=0.007$; OR 4.24, 95\% CI 1.55 to 13.60$)$, an increased BMI ( $p=0.029$; OR 1.12, 95\% CI 1.01 to 1.24$)$ and a short disease duration ( $p=0.029$; OR $0.92,95 \%$ CI 0.85 to 0.99 ) as predictors for these skin lesions. Based on the results of our multiple logistic regression model, we calculated probabilities for developing psoriasiform skin lesions depending on these three major predictorssmoking, BMI and disease duration, which are shown in figure 1 for a disease duration of 1 and 10 years, respectively. The association with short disease duration could also be related to a more severe disease phenotype in patients with psoriasiform skin lesions, resulting in a faster ('step-up') use of anti-TNF agents. This is supported by higher percentages of patients with stenoses and fistulas in the group with psoriasiform skin lesions; however, these differences were statistically not significant compared with the patient group without skin lesions. In addition, there was a trend for higher use of adalimumab in the group with skin lesions $(52.4 \%)$ compared with the group without skin lesions $(32.2 \% ; \mathrm{p}=0.06)$ which may also be related to more severe disease and infliximabrefractory IBD in patients with skin lesions.

\section{Incidence of non-psoriasiform skin lesions in anti-TNF-treated patients with IBD}

In 78 of 434 patients in the study group (18.0\%), nonpsoriasiform skin lesions or transient skin reactions including eczematiform skin lesions, skin infections, allergic injection site

Table 1 Comparison of demographic and clinical characteristics of anti-TNF-treated patients with IBD with and without anti-TNF-induced psoriasiform skin lesions (univariate analysis)

\begin{tabular}{|c|c|c|c|c|c|}
\hline & $\begin{array}{l}\text { Anti-TNF-treated patients with IBD without } \\
\text { psoriasiform skin lesions }(n=413)\end{array}$ & $\begin{array}{l}\text { Anti-TNF-treated patients with IBD with } \\
\text { psoriasiform skin lesions }(n=21)\end{array}$ & p Value & OR & $95 \% \mathrm{Cl}$ \\
\hline Median age (years), $n=434$ & 38.0 & 31.0 & 0.48 & 0.99 & 0.95 to 1.02 \\
\hline IQR & $28.0-47.0$ & $28.0-44.0$ & & & \\
\hline Gender ( $\%$ women), $n=433$ & $201(48.8 \%)$ & $11(52.4 \%)$ & 0.75 & 1.15 & 0.48 to 2.83 \\
\hline Crohn's disease, $n=434$ & $312(75.5 \%)$ & $19(90.5 \%)$ & 0.14 & 3.08 & 0.87 to 19.51 \\
\hline Ulcerative colitis, $n=434$ & $101(24.5 \%)$ & $2(9.5 \%)$ & 0.14 & 0.33 & 0.05 to 1.15 \\
\hline Stenosis, $n=414$ & $227(57.8 \%)$ & $14(66.7 \%)$ & 0.42 & 1.46 & 0.59 to 3.93 \\
\hline Fistulas, $n=411$ & $175(44.9 \%)$ & $13(61.9 \%)$ & 0.13 & 2.00 & 0.82 to 5.15 \\
\hline Median IBD duration (years), $n=431$ & 10.0 & 7.0 & 0.049 & 0.94 & 0.87 to 0.99 \\
\hline IQR & $5.0-18.0$ & $3.0-11.0$ & & & \\
\hline Median BMI $\left(\mathrm{kg} / \mathrm{m}^{2}\right), \mathrm{n}=384$ & 22.7 & 24.9 & 0.007 & 1.13 & 1.03 to 1.24 \\
\hline IQR & $20.0-25.5$ & $23.4-27.3$ & & & \\
\hline $\begin{array}{l}\text { History of smoking or active } \\
\text { smoking, } n=408\end{array}$ & $165(42.6 \%)$ & $16(76.2 \%)$ & 0.005 & 4.31 & 1.65 to 13.38 \\
\hline Treatment with infliximab, $n=434$ & $387(93.7 \%)$ & $21(100.0 \%)$ & 0.36 & $N / A^{*}$ & $N / A^{*}$ \\
\hline Treatment with adalimumab, $n=425$ & $130(32.2 \%)$ & $11(52.4)$ & 0.06 & 2.32 & 0.95 to 5.70 \\
\hline IQR & $3.0-13.0$ & $5.0-13.25$ & & & \\
\hline $\begin{array}{l}\text { Treatment with azathioprine or } \\
6 \text {-mercaptopurine, } n=426\end{array}$ & $377(93.1 \%)$ & $19(90.5 \%)$ & 0.65 & 0.71 & 0.19 to 4.57 \\
\hline
\end{tabular}


A

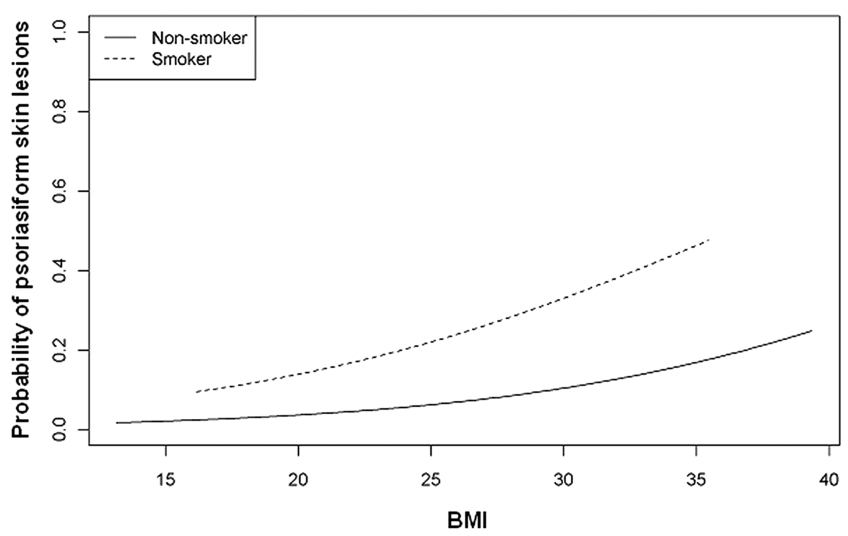

B Assumed disease duration: 10 years

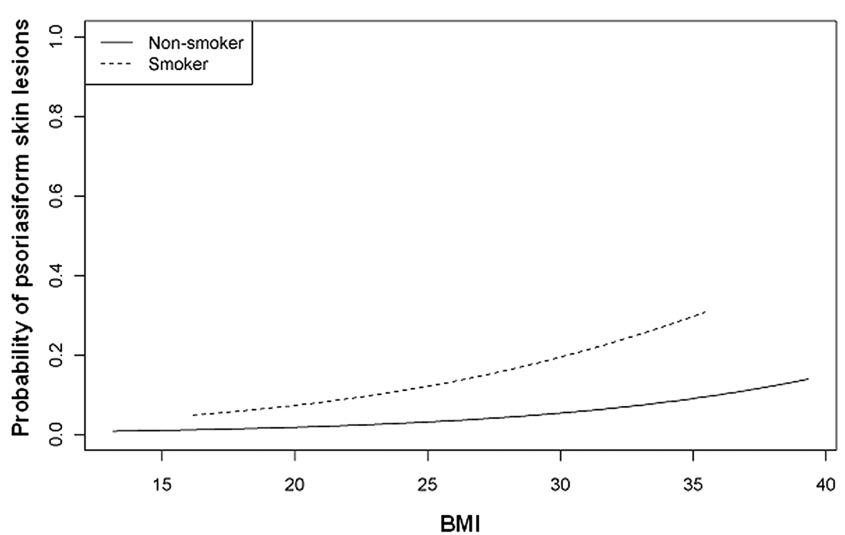

Figure 1 Probability plots for developing psoriasiform skin lesions based on the three main predictors identified in the multivariate analysis (smoking status, body mass index (BMI), disease duration). (A) Probability of developing psoriasiform skin lesions based on smoking status, BMI and an assumed disease duration of 1 year. (B) Probability of developing psoriasiform skin lesions based on smoking status, BMI and an assumed disease duration of 10 years. Smoking includes active smokers and ex-smokers.

reactions to adalimumab or transient skin reactions (eg, erythema) due to infliximab-related infusion reactions were observed (see online supplementary table S2). The most common nonpsoriasiform skin disorders were infusion reactions to infliximab with skin erythema $(5.8 \%)$, followed by viral skin infections $(2.5 \%)$, eczematiform skin lesions $(2.1 \%)$, xerosis cutis $(2.1 \%)$ and bacterial skin infections (1.4\%).

\section{Clinical subtypes of psoriasiform skin lesions observed in anti-TNF-treated patients with IBD}

Next, we further characterised the 21 patients who developed psoriasiform skin lesions under anti-TNF therapy. Some of the patients with psoriasiform skin lesions showed skin manifestations of different subtypes simultaneously (figure 2). The most common psoriasiform skin lesions were palmoplantar lesions $(n=11)$ and guttate psoriasis $(n=7)$ (figure 2). Of the 11 patients with anti-TNF-induced palmoplantar lesions, 8 were diagnosed with palmoplantar psoriasis, while 3 were affected by pustular palmoplantar psoriasis type Barber-Königsbeck. In nine patients, typical psoriasiform lesions were seen on the scalp.
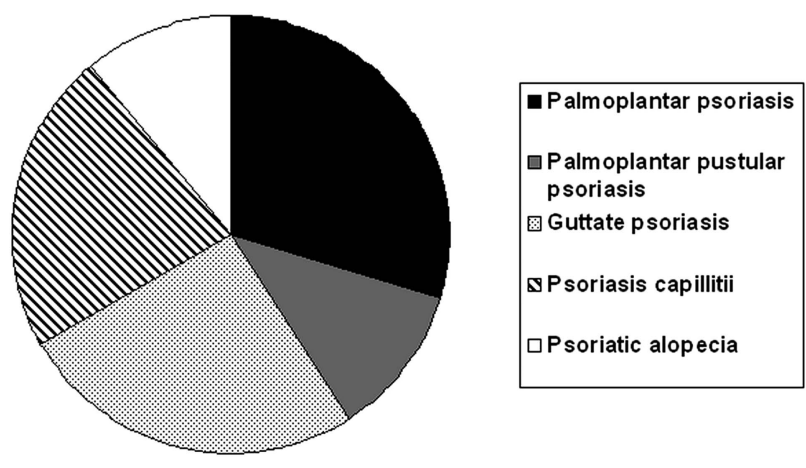

Figure 2 Spectrum of anti-tumour necrosis factor (TNF)-induced psoriasiform skin lesions. The figure represents the affected skin areas in the 21 patients with anti-TNF psoriasiform skin lesions. Nine patients had psoriasis capillitii-like lesions $(n=6)$ or alopecia $(n=3)$. Out of these nine patients, $n=1$ had guttate psoriasis, $n=1$ palmoplantar pustular psoriasis, $n=2$ palmoplantar psoriasis, while in three patients the main diagnosis was alopecia $(n=1)$ or psoriasis capilliti-like lesion $(n=2)$. Therefore, the diagram represents 27 affected skin areas in 21 patients (palmoplantar psoriasis: $n=8$; palmoplantar pustular psoriasis: $n=3$; guttate psoriasis: $n=7$; psoriasis capillitti: $n=6$; psoriatic alopecia: $n=3$ ).
Three of these patients developed an additional diffuse alopecia (see details in the online supplementary information).

\section{Lupus-associated autoantibodies in patients with anti-TNF-induced psoriasiform skin lesions}

Anti-TNF-induced skin lesions do not always completely follow a psoriasiform pattern, but also share in some cases clinical characteristics of lupus erythematosus. Although IFN- $\alpha$ has been suggested as a key cytokine in the pathogenesis of psoriasiform skin lesions, ${ }^{29}$ it plays also a key role in the pathogenesis of cutaneous discoid lupus erythematosus. We therefore analysed lupus-associated autoantibodies in all patients with psoriasiform skin lesions. A common feature found in $85.7 \%$ of patients with these skin lesions was elevated titres of antinuclear antibodies (ANAs). This percentage was not significantly higher than in anti-TNF-treated patients with IBD without skin lesions (figure $3 \mathrm{~A}$, online only). Of the 21 patients with skin lesions, only 3 had non-detectable ANA titre. One-third of the patients with psoriasiform skin lesions (33.3\%) had high ANA titres of at least 1:1920, another third had titres between 1:240 and $1: 960$ and the remaining third had titres below $1: 240$ or no detectable ANA titres. Nominally, there was a higher percentage of patients with ANA titres $>1: 960$ in the group of patients with psoriasiform skin lesions compared with patients without skin lesions receiving anti-TNF agents (33.3\% vs $13.7 \%)$; however, this difference was statistically not significant $(\mathrm{p}=0.1555$; figure $3 \mathrm{~A}$, online only). Three patients with psoriasiform skin lesions and elevated ANA titres showed lupus-like features in the skin biopsies or during the dermatological examination (table 2, online only). In five patients (23.8\%) with psoriasiform skin lesions, anti-dsDNA antibodies $>9 \mathrm{U} / \mathrm{ml}$ were detected. However, in all cases the anti-dsDNA titres were lower than $23 \mathrm{U} / \mathrm{ml}$ and clinical signs of anti-TNF-induced lupus-like syndrome (eg, arthralgias, swollen joints) were found in only one patient. Overall, the distribution of dsDNA titres in patients with anti-TNF-induced psoriasiform skin lesions was statistically not different from the titre distribution in patients with IBD without anti-TNF-induced skin lesions (figure $3 \mathrm{~B}$, online only).

\section{Efficacy of switching anti-TNF antibodies (infliximab vs} adalimumab) for treatment of anti-TNF-induced skin lesions All 21 patients who developed psoriasiform skin lesions had been treated or were actively treated with infliximab. In 
16 patients, skin lesions developed under the current therapy with infliximab, in 5 patients under adalimumab therapy (figure 4). In three patients with infliximab-induced psoriasiform skin lesions, therapy was switched to adalimumab due to skin lesions. However, the change of the anti-TNF antibody resulted in a slight improvement in anti-TNF-induced psoriasiform skin lesions in only one patient, while the skin lesions worsened in one patient and another patient developed an allergy against adalimumab (figure 4). In the patient with worsened skin lesions under adalimumab therapy, treatment was switched to certolizumab. However, the skin lesions did not improve under certolizumab therapy. Therefore, our results suggest that psoriasiform skin lesions may develop under all anti-TNF agents, suggesting that this is likely a class-dependent effect and not specific for a certain anti-TNF antibody. Therefore, switching between different anti-TNF antibodies because of anti-TNF-induced skin lesions has limited therapeutic efficacy.
The different therapeutic strategies applied in the 21 patients with psoriasiform skin lesions are shown in figure 4 .

Anti-TNF therapy-induced psoriasiform skin lesions and anti-TNF-induced alopecia respond to anti-IL-12/IL-23 antibody treatment with ustekinumab

Considering the successful use of ustekinumab in patients with plaque psoriasis, ${ }^{30-32}$ we switched the treatment of patients with severe psoriasiform skin lesions, requiring cessation of anti-TNF therapy and lacking response to topical anti-psoriatic treatment, from TNF blockers to ustekinumab. Ustekinumab is a monoclonal antibody directed against the p40 subunit of IL-12 and IL-23. In total, $n=7$ patients were treated at the Munich IBD centre with ustekinumab (figure 4). All seven patients (100\%) treated with ustekinumab showed a marked improvement in their skin lesions using this IL-12/IL-23 antibody. All ustekinumab-treated patients had severe anti-TNF-
Figure 4 Therapeutic strategies in the 21 patients with anti-tumour necrosis factor (TNF)-induced psoriasiform skin lesions found in the Munich inflammatory bowel disease (IBD) cohort of 434 anti-TNF-treated patients. In addition to the seven patients treated with ustekinumab from the Munich cohort, two patients with IBD with anti-TNF-induced skin lesions from the Medical University of Vienna were successfully treated with ustekinumab. ADA, adalimumab; IFX, infliximab.

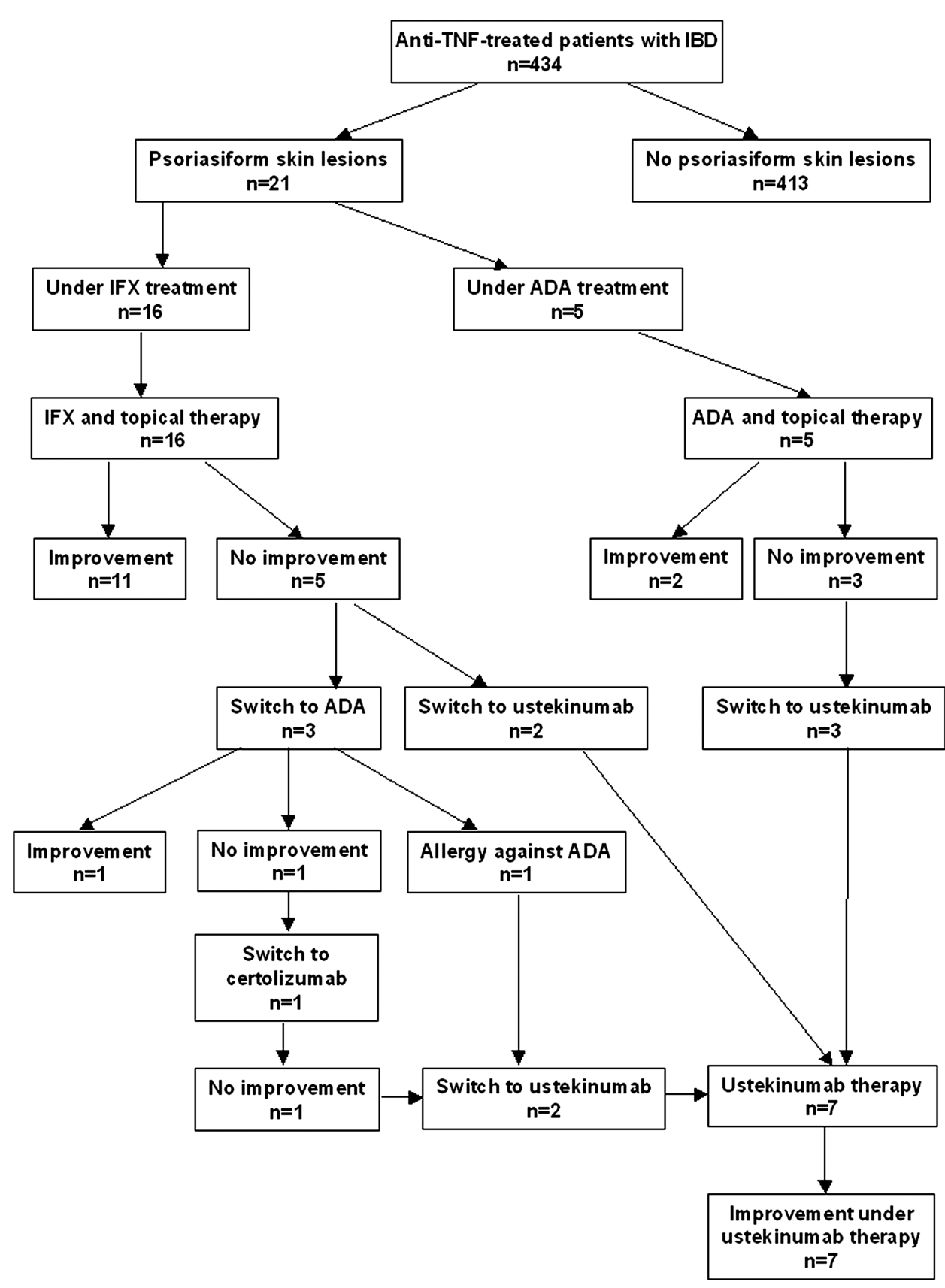


Downloaded from http://gut.bmj.com/ on May 3, 2017 - Published by group.bmj.com

Inflammatory bowel disease

Table 3 Clinical and demographic details of patients treated with the anti-IL-12/IL-23 antibody ustekinumab

\begin{tabular}{llllllll}
\hline Patient no. & Age & Sex & Type of IBD & Type of skin lesions & CDAl before ustekinumab & CDAl at week 16* & Change of skin lesions \\
\hline 2 & 28 & M & CD & Palmoplantar pustular psoriasis, psoriasis capillitii & N/A & 84 & + \\
3 & 27 & F & CD & Diffuse alopecia & 0 (complete remission) & 0 (complete remission) & +++ \\
9 & 22 & M & CD & Palmoplantar psoriasis, alopecia & 62 & 101 & ++ \\
11 & 20 & M & CD & Guttate psoriasis, psoriasis capillitii & 69 & $69 \dagger$ & ++ \\
12 & 30 & F & CD & Pustular palmoplantar psoriasis & 49 & $183 \neq$ & ++ \\
14 & 61 & M & CD & Psoriasis capillitii, features of psoriasis and LE & 0 (complete remission) & $50 \S$ & ++ \\
20 & 40 & F & CD & Palmoplantar psoriasis, psoriasis capillitii & 313 & $214 \uparrow$ & ++ \\
A & 48 & F & CD & Palmoplantar psoriasis with nail involvement & 279 & 103 & ++ \\
B & 31 & F & CD & Psoriasis inversa & 341 & 348 & +++ \\
\hline
\end{tabular}

Severity of Crohn's disease was evaluated by using the Crohn's Disease Activity Index (CDAI). Clinical improvement of psoriasiform skin lesion was determined by an independent dermatologist using a semiquantitative score (- worsened; 0 no change; + slight improvement; ++ marked improvement; +++ healed).

${ }^{*} \mathrm{CDAI}$ was calculated at week 16 after two ustekinumab injections (on the day of the third ustekinumab injection but before the third ustekinumab injection).

tThe patient is a stoma carrier. Therefore, the CDAI of this patient is shown without including the score for stool frequency into the total CDAI score.

¥At week 16, the patient was diagnosed with Campylobacter jejuni infection.

§Three ustekinumab injections ( $45 \mathrm{mg}$ at week $0,45 \mathrm{mg}$ at week 4, $90 \mathrm{mg}$ at week 10 ).

IPrior to week 16, the patient was treated with prednisolone due to a disease flare ( $20 \mathrm{mg}$ for 1 week and then reducing the dose by $2.5 \mathrm{mg}$ per week).

$\mathrm{CD}$, Crohn's disease; $\mathrm{f}$, female; IBD, inflammatory bowel disease; $\mathrm{m}$, male.

induced palmoplantar psoriasis or anti-TNF-induced alopecia. Detailed disease characteristics of all the patients are given in the online supplementary information and are summarised in table 3. Representative images of the skin lesions and their improvement under ustekinumab therapy are shown in figures 5-9 (figures 5, 7 and 8 online only). Interestingly, all ustekinumab-treated patients who had severe psoriasiform lesions were patients with CD.

\section{Confirmation of the treatment efficacy of ustekinumab in an independent patient cohort}

Based on our treatment success of ustekinumab in anti-TNFinduced psoriasiform skin lesions, we also treated two patients with adalimumab-induced psoriasiform skin lesions from an independent patient cohort (IBD centre of the Medical
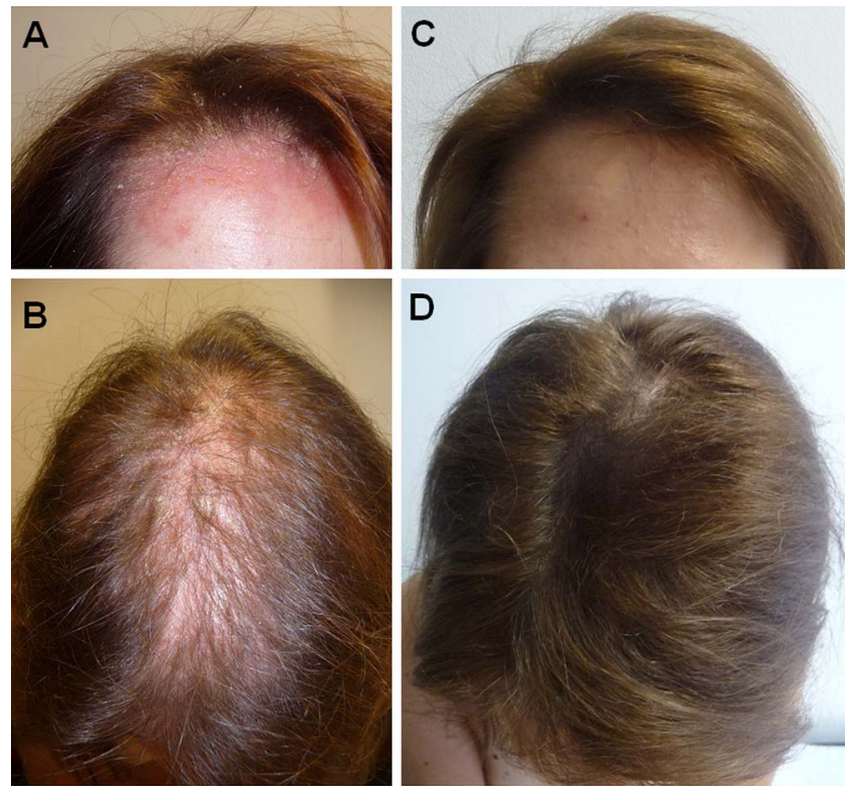

Figure 6 Severe anti-tumour necrosis factor-induced alopecia in a woman with Crohn's disease. (A) Psoriasiform skin lesions in the frontal scalp region. (B) Severe loss of hair in the vertex region after three injections of adalimumab. (C) and (D) Complete healing after three injections of ustekinumab.
University Vienna) with the anti-IL-12/23 antibody ustekinumab. Details of both patients (patient A and patient B) are given in the online supplementary information and are summarised in table 3. Representative images are shown in figure 10 (online only). In both patients, the skin lesions showed an excellent response to treatment with ustekinumab.

\section{CD activity under ustekinumab therapy}

The activity of CD was monitored in all nine patients treated with ustekinumab and is shown for the first 16 weeks of ustekinumab treatment in table 3. At start of ustekinumab therapy, six patients were in remission (defined as CD Activity Index (CDAI)
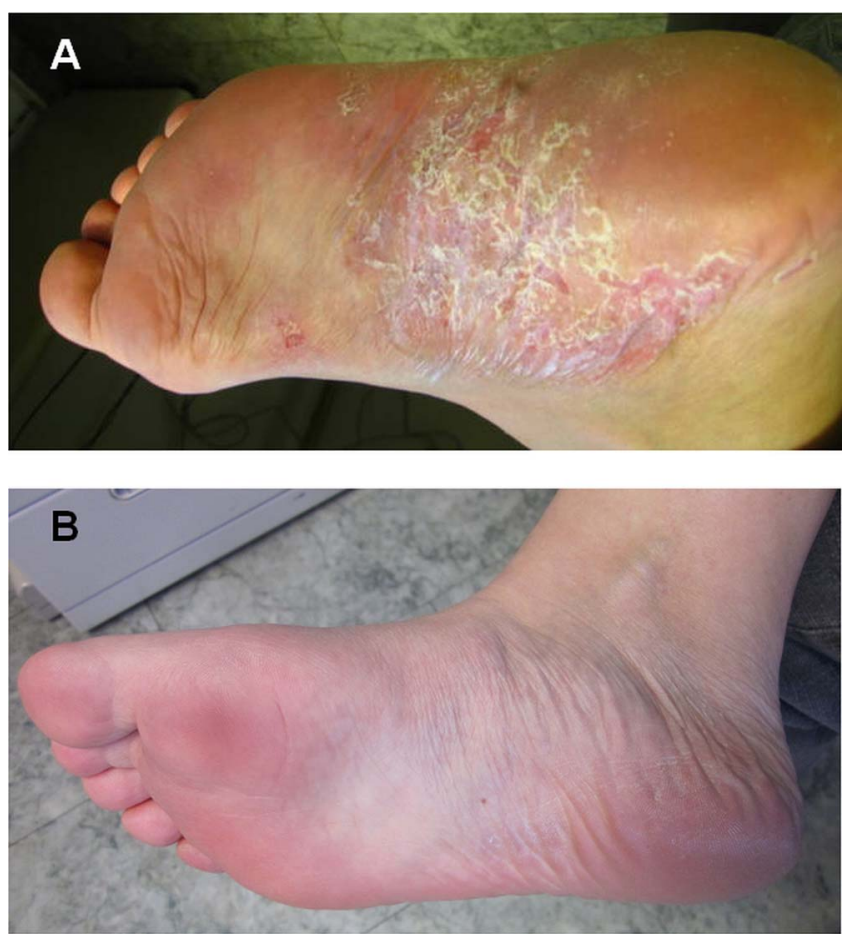

Figure 9 Woman with severe anti-tumour necrosis factor-induced palmoplantar psoriasiform skin lesions. (A) Severe infliximab-induced plantar psoriasiform skin lesion. (B) Complete healing of the lesions after therapy with ustekinumab and alitretinoin. 
$<150)$, while three patients $(33.3 \%)$ had active disease. At week 16 after the start of ustekinumab, the percentage of patients with active disease was unchanged (33.3\%), although two patients with active disease at week 0 had a significant decrease in their CDAI and one of these patients reached remission at week 16. Conversely, one patient who was in remission at week $0(\mathrm{CDAI}=49)$ had an increase in disease activity $(\mathrm{CDAI}=183)$ at week 16 (table 3). However, this patient was also diagnosed as having a Campylobacter jejuni infection at week 16, suggesting that the disease flare was (at least partially) caused by the Campylobacter infection.

\section{Analysis of IBD- and psoriasis-associated IL23R, IL23A and IL12B gene variants}

Considering the excellent treatment response seen with the anti-IL-12/IL-23 antibody ustekinumab in all patients with anti-TNF-induced skin lesions and the association of IL23R and IL12B gene variants with both IBD and psoriasis, ${ }^{15-17}$ we next analysed whether IL23R, IL12B and IL23A gene variants are associated with anti-TNF-induced psoriasiform skin lesions. In our study, none of the patients had a family member with severe psoriasis, which is statistically not different from the number of expected psoriasis-affected family members $(n<1$, based on a psoriasis prevalence of a maximum of $5 \%$ in IBD populations and $2 \%$ in the general population; $\mathrm{p}=1.000$, Fisher's exact test). Interestingly, in the study by Rahier et al, ${ }^{4} 12.9 \%$ of the patients with IBD with psoriasiform skin lesions had a positive family history of psoriasis, which supports the hypothesis of common susceptibility genes shared with psoriasis. Previously, we and others demonstrated for 10 IL23R SNPs strong associations with CD and partly also with UC, ${ }^{15}{ }^{16}$ and an association with IL-22 serum levels. ${ }^{9}$ Five of these 10 IL23R variants increased the IBD risk, while five other variants decreased the IBD risk. ${ }^{16}$ We therefore analysed whether these $I L 23 R$ variants are associated with psoriasiform skin lesions in patients with IBD (table 4, online only). However, none of these variants was overrepresented in patients with psoriasiform skin lesions. Similarly, we did not find significant differences in the minor allele frequencies of $I L 12 B$ and IL23A variants (table 4, online only), for which associations with IBD and/or psoriasis were demonstrated previously. ${ }^{17}$ 33-35 However, all patients with severe psoriasiform skin lesions and/or anti-TNF-induced alopecia, requiring ustekinumab therapy from the Munich IBD centre, were $\mathrm{G} / \mathrm{G}$ wildtype carriers for the rare coding IL23R variant rs11209026 (p.Arg381Gln). The wildtype status of this SNP is associated with increased Th17 cytokine production, ${ }^{36-}$ 38 while in carriers of the minor allele, the secretion of Th17 cytokines such as IL-22 is decreased. ${ }^{9}$ Similarly, there was a trend towards a higher number of $\mathrm{C} / \mathrm{T}$ heterozygotes of the IL23R SNP rs7530511 (p.Leu310Pro) in the seven patients with severe skin lesions requiring ustekinumab therapy compared with anti-TNF-treated patients with IBD without skin lesions $(42.9 \%$ vs $21.6 \% ; \mathrm{p}=0.05)$.

\section{Severe anti-TNF antibody-induced psoriasiform skin lesions are characterised by infiltrates of IFN $\gamma$-expressing Th1 cells and IL-17A/IL-22-expressing Th17 cells, and the IL-17A expression correlates with the requirement for ustekinumab therapy}

Given the response of all patients to anti-IL-12/IL-23 treatment, the requirement of IL-23 for differentiation of Th17 cells, and the G/G wildtype status of IL23R SNP rs11209026 (p.Arg381Gln) in all patients with severe psoriasis requiring ustekinumab, we performed a detailed histological analysis of skin lesions regarding Th17 cell infiltrates in patients with severe new-onset psoriasiform lesions. Representative images of the immunohistochemical analysis including staining of control patients with genuine (ie, not anti-TNF- $\alpha$ induced) plaque psoriasis are shown in figure 11 (online only) and online supplementary figure S1. Characteristic histological features found in the majority of patients with psoriasiform skin lesions who underwent skin biopsy sampling were acanthosis, parakeratosis and hyperkeratosis, neutrophil infiltrates in the epidermis and lymphohistiocytic infiltrates in the dermis (online supplementary figure S1A; table 2, online only). The inflammatory cell infiltrate in the skin was composed mainly of lymphocytes (figure 11A online; online supplementary figure S1B) and particularly of CD4 lymphocytes (figure 11B online; online supplementary figure S1C). In most patients, infiltrates of IL-17A-secreting $\mathrm{T}$ cells (figure 11C online; online supplementary figure S1D) and IL-22-secreting $T$ cells (figure 11D online; online supplementary figure S1E) were detected. This cytokine profile (IL-17A+/IL-22+) is characteristic of Th17 cells. ${ }^{39}$ In addition, we found strong infiltrates of IFN- $\gamma$-expressing Th1 cells in all patients (figure 11E online; online supplementary figure S1F). We also found positive immunostaining for IFN- $\alpha$ (figure $11 \mathrm{~F}$ online; online supplementary figure $\mathrm{S} 1 \mathrm{G}$ ), which has been implicated in the pathogenesis of anti-TNF-induced psoriasiform skin lesions, and immunostaining for TNF- $\alpha$ (figure $11 \mathrm{G}$ online; online supplementary figure $\mathrm{S} 1 \mathrm{H})$, which has also been found to be a key player in the pathogenesis of genuine (ie, not anti-TNF-induced) psoriasis. ${ }^{40}$

We performed semiquantitative analysis of immunostaining for all antibodies used in this analysis (CD3, CD4, IL-17A, IL-22, IFN- $\gamma$, IFN- $\alpha$, TNF- $\alpha$; figure 12) and compared the cytokine expression levels in patients with anti-TNF- $\alpha$-induced psoriasiform skin lesions requiring ustekinumab with those of patients who did not require ustekinumab. We also included tissue from patients with non-anti-TNF- $\alpha$-induced genuine plaque psoriasis as controls, which showed a slightly denser CD3 lymphocytic infiltrate than anti-TNF-induced psoriasiform skin lesions but showed no significant differences in the expression of the investigated cytokines in comparison to biopsy tissue from patients with anti-TNF-induced psoriasiform skin lesions (figure 12). The only significant difference between patients requiring ustekinumab compared with those not requiring ustekinumab was higher expression levels of infiltrating IL-17A+ T cells $(p=0.001$; figure $12 \mathrm{C})$. All patients with moderate and severe IL-17A staining (score 2 or 3 ) had very severe skin lesions requiring systemic ustekinumab therapy, while only one of the seven patients in the group with weak or no IL-17A staining required systemic ustekinumab therapy $(p=0.0047$, Fisher's exact test for comparing the requirement of ustekinumab therapy between the group with an IL-17A staining score of 0 or 1 vs the group with a score of 2 and 3 combined; figure $12 \mathrm{H}$ ).

\section{DISCUSSION}

In this study, we demonstrate that anti-TNF antibodies, which are approved for the treatment of psoriasis, may paradoxically cause psoriasiform skin lesions in patients with IBD. This study contributes significantly to our understanding of these lesions and differs from previous retrospective case series for a number of reasons. In contrast to previous studies, the data were collected prospectively and all patients with skin lesions were seen by the same board-certified dermatologist. This allowed for the calculation of incidence rates of these lesions. We identified smoking as the major risk factor for these lesions. In addition, 

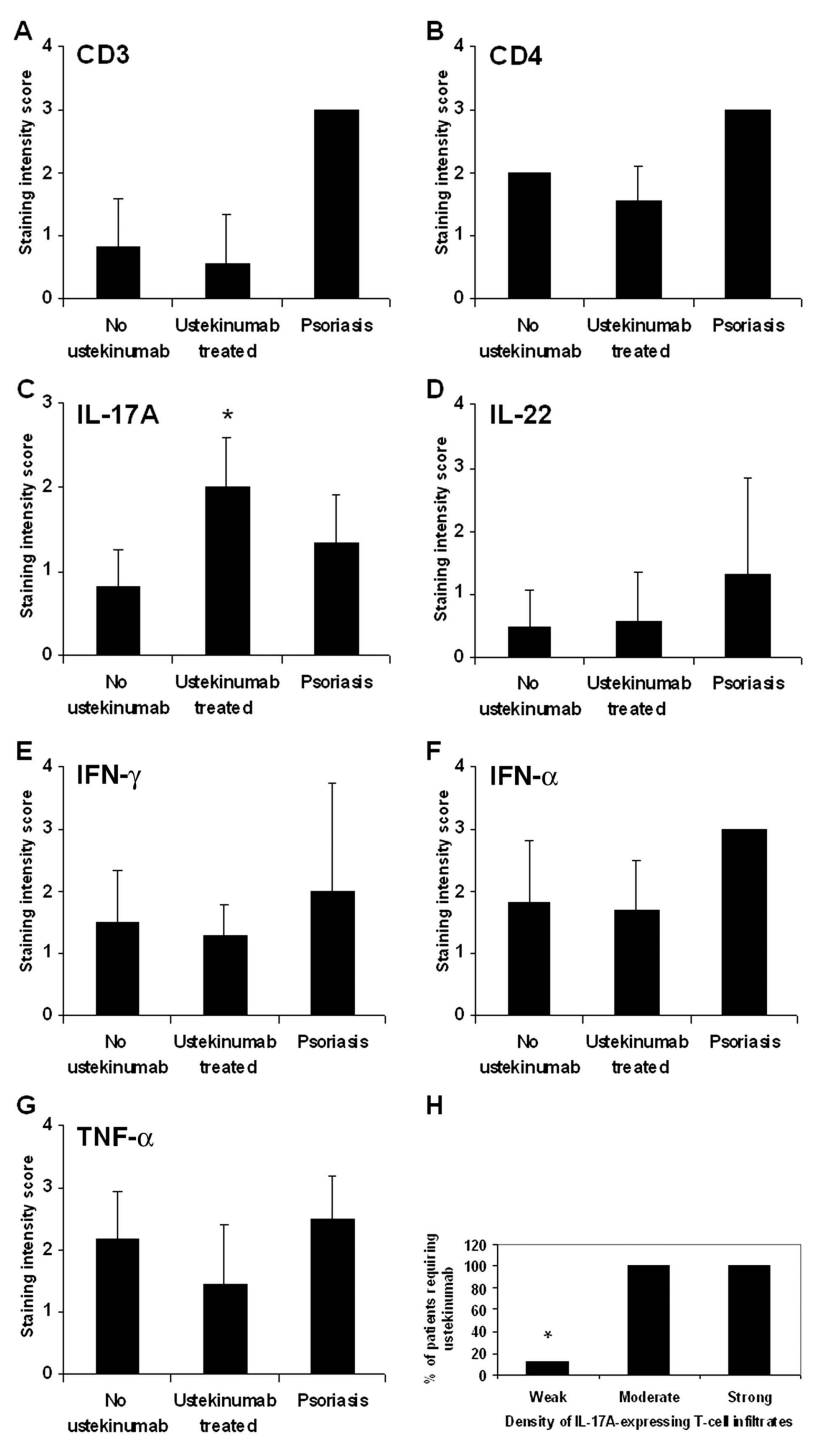

H

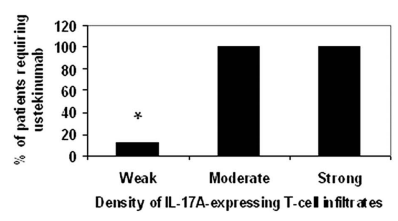

Figure 12 Semiquantitative analysis of immunohistochemical staining of anti-tumour necrosis factor (TNF)-induced psoriasiform skin lesions. Semiquantitative analysis of (A) CD3, (B) CD4, (C) IL-17A ( ${ }^{*} p=0.001$ for ustekinumab treated vs no ustekinumab), (D) IL-22, (E) IFN- $\gamma$, (F) IFN- $\alpha$ and (G) TNF- $\alpha$ staining. The semiquantitative analysis was performed blind to the clinical disease characteristics and blind to the information of ustekinumab therapy. All 13 patients who underwent biopsy sampling are included in this analysis. The staining intensity was compared between patients with inflammatory bowel disease with anti-TNF-induced skin lesions requiring ustekinumab (before ustekinumab therapy; $n=7$ ) and patients without the need for ustekinumab $(n=6)$. Patients with genuine (not anti-TNF induced) plaque psoriasis $(n=3)$ served as controls. Semiquantitative evaluation of the immunohistochemical stainings was performed using the following grading: no staining (0), weak positive staining (1), moderate positive staining (2) and strong positive staining (3) for the respective antibody. (H) All patients with moderate or severe IL-17A staining were found in the group of patients with anti-TNF-induced psoriasiform skin lesions requiring ustekinumab $(p=0.0047$, Fisher's exact test for comparing the requirement of ustekinumab therapy between the group with an IL-17A staining intensity score of 0 or 1 vs the group with a score of 2 and 3 combined). IFN, interferon; IL, interleukin.

this study contains a detailed histopathological analysis and provides, for the first time, evidence that Th1 and Th17 cells play a key role in the pathogenesis of these lesions, suggesting similarities in the pathogenesis of anti-TNF-induced psoriasiform skin lesions and that of psoriasis. We also provide first proof of principle that anti-IL-12/anti-IL-23 antibody therapy, which is directed against Th1 and Th17 cells, is highly effective in patients with severe anti-TNF-induced psoriatic skin lesions. In addition, we performed a detailed genotype analysis of IBD- and psoriasis-associated IL23R, IL23, IL12B gene variants in patients with anti-TNF-induced skin lesions.

Psoriasiform and eczematiform skin lesions are the most frequently observed dermatological adverse events in patients treated with anti-TNF antibody. ${ }^{4} 4142$ Several case series analysing severe skin lesions in patients with IBD caused by anti-TNF inhibitors have been published. ${ }^{4} 643-47$ Due to the retrospective nature of the majority of previous studies, the exact prevalence of psoriasiform skin lesions in patients receiving anti-TNF antibodies is largely unknown. In our prospective study, almost $5 \%$ of all anti-TNF-treated patients developed psoriasiform skin lesions, which is consistent with data derived from anti-TNF-treated patients with rheumatoid arthritis. ${ }^{48}$ Rahier et $a l^{4}$ extrapolated data from a French IBD centre and suggested that the risk of developing inflammatory skin lesions (psoriasiform or eczematiform) is around 5\% in anti-TNFtreated patients with IBD and the definitive need to withdraw anti-TNF treatment due to uncontrolled skin lesions is around $1 \%$. Similarly, in our study, in 7 of 434 anti-TNF-treated patients with IBD (1.6\%) anti-TNF treatment had to be stopped due to severe skin lesions. In our study, most patients with psoriasiform lesions had palmoplantar psoriasis, which was also one of the most common skin manifestations in other studies. $^{4} 6$

Similar to our study, in which $90.5 \%$ of patients with anti-TNF-induced psoriasis had CD, the majority of patients in other studies were diagnosed with CD and not UC. ${ }^{4}{ }^{6}$ This is in agreement with the clinical observation that there is a stronger overlap between psoriasis and CD compared with UC, which may be related to the stronger association of $\mathrm{CD}$ and psoriasis with IL23R and IL12B SNPs than observed in UC. ${ }^{16}{ }^{17}$ However, considering the later approval for infliximab and adalimumab for the treatment of UC (compared with CD), this may partially reflect a prescription bias of anti-TNF inhibitors in patients with IBD.

Smokers seem to be especially prone to psoriasiform skin lesions. In our study, $76.2 \%$ of the patients with psoriasiform skin lesions were active smokers or ex-smokers. In multivariate analysis, being a smoker or having a history of smoking was the strongest predictive factor for developing psoriasiform skin lesions ( $p=0.007$; OR 4.24, 95\% CI 1.55 to 13.60). In addition, we identified an increased BMI as a risk factor for developing these lesions ( $\mathrm{p}=0.029$; OR 1.12, 95\% CI 1.01 to 1.24). Interestingly, smoking and an increased BMI have also been shown to increase the risk for psoriasis, ${ }^{49}$ suggesting similarities in the disease pathogenesis of anti-TNF-induced psoriasiform skin lesions and psoriasis.

We had to stop anti-TNF therapy in 7 of 21 patients with skin lesions $(33.3 \%)$ due to the severity of lesions and the lack of efficacy of topical therapy. In the study by Rahier et al, ${ }^{4} 40 \%$ of the patients had to stop anti-TNF therapy despite a number of other therapeutic manipulations. Similarly, in our study, switching from infliximab to adalimumab improved the skin lesions only in one patient, while in another patient the skin lesions did not improve after switching from infliximab to adalimumab and then to certolizumab. Discontinuing anti-TNF therapy as a major part of treatment of anti-TNF antibody-induced palmoplantar pustulosis has also been described in the Mayo study and other case reports. ${ }^{43} 50$ Overall, all currently approved anti-TNF inhibitors 
may cause psoriasiform skin lesions, suggesting that this is a class-related side effect. In our study, the majority of patients with skin lesions were treated with infliximab. However, this may reflect the earlier approval and longer use of infliximab, which is also shown by the fact that more patients without skin lesions were treated with infliximab than adalimumab.

To unravel genetic risk factors associated with anti-TNFinduced psoriasiform skin lesions, we performed a detailed genotyping analysis of IBD- and psoriasis-associated IL23R and IL12B gene variants. Although there were nominally no significant differences in the minor allele frequencies of these gene variants when anti-TNF-treated patients with IBD with and without skin lesions were compared, all patients with severe psoriasiform skin lesions and/or anti-TNF-induced alopecia requiring ustekinumab therapy were $\mathrm{G} / \mathrm{G}$ wildtype carriers for the rare coding IL23R variant rs11209026 (p.Arg381Gln). In contrast to carriers of the rare minor A allele, this is associated with higher Th17 cytokine production, ${ }^{51}$ suggesting a role of Th17 cells in the pathogenesis of these skin lesions. A role for IL23R in the disease pathogenesis of psoriasiform skin lesions has also been suggested by a study of a smaller paediatric IBD cohort. ${ }^{52}$

Currently, the pathogenesis of psoriasiform skin lesions caused by anti-TNF therapy is only poorly understood. Considering that TNF- $\alpha$ plays a key role in the pathogenesis of IBD and psoriasis, the occurrence under anti-TNF therapy seems to be paradoxical. According to one hypothesis, plasmacytoid dendritic cells (pDCs) may play a role in the formation of anti-TNF antibody induced psoriasiform lesions. ${ }^{53}$ pDCs have been described by us in psoriasis lesions for the first time ${ }^{54}$ and are known producers of IFN- $\alpha$. TNF- $\alpha$ inhibits pDC maturation from haematopoietic progenitor cells and consequently inhibits IFN- $\alpha$ production. ${ }^{55}$ Therefore, anti-TNF treatment may result in unlimited IFN- $\alpha$ production by pDCs. In agreement with this hypothesis, we found IFN- $\alpha$ protein expression in all patients who underwent skin biopsy for sampling anti-TNF-induced psoriasiform skin lesions. Similarly, increased IFN- $\alpha$ expression has been found in the skin vasculature and in perivascular lymphocytic infiltrates of skin lesions in patients treated with anti-TNF antibodies. ${ }^{55}$ However, our immunohistochemical staining also demonstrates TNF- $\alpha$ expression in the majority of patients. This suggests that despite TNF- $\alpha$ inhibition being a trigger for psoriasiform skin lesions, TNF- $\alpha$ participates in the secondary inflammatory skin reaction which is similar to genuine psoriasis ${ }^{40}$ and consistent with our analysis of TNF- $\alpha$ expression in patients with genuine psoriasis (figure 12G). Other studies suggested that altered lymphocyte migration caused by anti-TNF treatment may also contribute to skin lesions through the expression of CXCR3 ligands. ${ }^{29}$ We recently demonstrated increased expression of CXCR3 ligands in active IBD, ${ }^{56}$ which may be an additional risk factor for developing these skin lesions.

In addition to these findings, our histological analysis revealed for the first time an increased number of IFN- $\gamma$-secreting Th1 and IL-17-/IL-22-secreting Th17 cells in anti-TNF-induced psoriasiform skin lesions. This is similar to the cytokine profile in genuine psoriasis, in which increased expression of the Th17 cytokines IL-17A and IL-22 has been demonstrated. ${ }^{14} 57$ Importantly, we found strong IL-17A expression significantly more often in very severe psoriasiform skin lesions requiring ustekinumab therapy than in less severe lesions responding to topical therapy. Two very recent studies demonstrated that antibody therapy directed against IL-17A or its receptor IL-17RA is effective in psoriasis. ${ }^{58} 59$ In addition to IL-17A, IL-22 plays a key role in the pathogenesis of psoriasis ${ }^{14} 4060$ and increases the expression of proinflammatory genes in keratinocytes. ${ }^{61}$
A clinical trial evaluating fezakinumab (ILV-094), an antibody directed against IL-22, has been initiated in patients with psoriasis. ${ }^{62}$ Psoriasis is histologically characterised by hyperplasia of the epidermis (acanthosis), infiltration of leukocytes into the dermis and epidermis, and dilation and growth of blood vessels, ${ }^{40} 63$ all features found in many of our patients who underwent skin biopsy sampling. A recent study demonstrated that IL-22 mediates IL-23-induced acanthosis and dermal inflammation through the activation of STAT3 (signal transduction and activators of transcription 3 ) in vivo, ${ }^{64}$ providing a rationale for anti-IL-23 and anti-IL-22 therapy in psoriasis. Based on our detailed histopathological analysis, we hypothesise that Th1 and Th17 cells play a major role in the disease pathogenesis of anti-TNF-induced psoriasiform skin lesions. Additional studies are required to clarify the effects of type I interferons on Th17 cytokines in the disease pathogenesis of these lesions. For example, worsening of Th17 cell-mediated psoriasis has been reported in patients with psoriasis and hepatitis $\mathrm{C}$ treated with type I IFN, ${ }^{65}$ while IFN- $\beta$ may inhibit Th17 cell differentiation in mice. ${ }^{66} 67$

This study is the first detailed report on the successful use of the anti-IL-12/IL-23 antibody ustekinumab for anti-TNFinduced psoriasiform skin lesions. Ustekinumab has been approved for the treatment of plaque psoriasis in the USA and Europe. Pilot trials and a large study indicate some efficacy in CD. ${ }^{23}$ In all nine patients treated with ustekinumab, psoriasiform skin lesions improved dramatically after the first two injections. Moreover, in the majority of these patients, CD activity was controlled with ustekinumab. However, it is likely that CD requires a higher ustekinumab dose than psoriasis for maintenance of remission, which is currently being investigated in ongoing trials. Inhibition of IL-23 also limits IL-17A and IL-22 production $^{64}$ and Th17 cytokine-induced skin and gut inflammation, while inhibition of IL-12 limits Th1-induced IFN- $\gamma$ expression. Due to the limited number of patients with psoriasiform skin lesions and considering the severity of skin lesions and the complicated IBD in most patients, our study does not contain a comparison group in which anti-TNF therapy was stopped. However, the results of Rahier $e t a l^{4}$ suggest that stopping anti-TNF therapy may be effective in many patients. Interestingly, in one of the nine ustekinumab-treated patients with psoriasiform skin lesions, there was a slight recurrence of these lesions at the end of the ustekinumab injection interval, which suggests that-at least in some patients-stopping anti-TNF therapy is not sufficient to completely heal these lesions. This could also be the case in patients who convert to 'true' (genuine) psoriasis, triggered by anti-TNF therapy.

In conclusion, new onset psoriasiform skin lesions develop in approximately $5 \%$ of anti-TNF-treated patients with CD. Active smoking or a history of being a smoker is the strongest predictive factor for developing psoriasiform skin lesions. These lesions are characterised by IFN- $\alpha$ expression and infiltrates of IL-17A/ IL-22-secreting Th17 cells and IFN- $\gamma$-secreting Th1 cells. Anti-IL-12/IL-23 antibody therapy is highly effective in treating anti-TNF-induced psoriasis and psoriasiform alopecia. Given the previously shown efficacy of anti-IL-12/IL-23 antibody therapy in $\mathrm{CD}$, ustekinumab may be a suitable alternative to anti-TNF therapy in patients with CD with anti-TNF-induced psoriasiform skin lesions.

\section{Author affiliations}

${ }^{1}$ Department of Medicine II—Grosshadern, Ludwig Maximilians University (LMU), Munich, Germany

${ }^{2}$ Department of Dermatology and Allergy, LMU Munich, Munich, Germany 
${ }^{3}$ Clinic for Preventive Dentistry and Parodontology, LMU Munich, Munich, Germany ${ }^{4}$ Institute of Medical Informatics, Biometry, and Epidemiology (IBE), LMU Munich, Munich, Germany

${ }^{5}$ Department of Internal Medicine III, Division of Gastroenterology and Hepatology, Medical University Vienna, Vienna, Austria

${ }^{6}$ Institute of Clinical Chemistry—Grosshadern, LMU Munich, Munich, Germany ${ }^{7}$ Department of Pediatrics, Medizinische Hochschule Hannover, Hannover, Germany ${ }^{8}$ Department of General Dermatology, Medical University Vienna, Vienna, Austria ${ }^{9}$ Department of Human Genetics, Rheinisch-Westfälische Technische Hochschule (RWTH) Aachen, Aachen, Germany

${ }^{10}$ Centre of Infection and Immunity, Queen's University Belfast, Belfast, UK

Acknowledgements This paper is part of the degree thesis of Matthias Friedrich.

Contributors Examination and treatment of patients: CT, AW, LME, PP, HV, HM FB, MK, SB. Genotyping: MF, JG, JD, JSt, JW, MW. Immunohistochemical analysis: $M F, A B, Y D, S K$, JSc. Statistical analysis: RPL, MF, SB. Design of the study: SB. Organising the collaboration between the different institutions: SB. Writing of the manuscript: SB, CT, LME, AW. CT, LME and MF share first authorship.

Funding $\mathrm{S}$. Brand was supported by grants from the Deutsche Forschungsgemeinschaft (DFG; BR 1912/6-1) and the Else-Kröner-Fresenius-Stiftung (Else Kröner-Exzellenzstipendium 2010_EKES.32). F. Beigel was supported by a grant from the Deutsche Forschungsgemeinschaft (DFG; BE 4490/2-1).

Competing interests C. Tillack, P. Papay, F. Beigel and S. Brand received honoraria for lectures from MSD and Abbott. J. Schauber received honoraria for lectures from Galderma, Pfizer, Meda Pharma and Bayer Consumer Healthcare. A. Wollenberg received honoraria for lectures from Amgen, Astellas, Basilea, GSK, Merck, MSD and Novartis.

Ethics approval Ethical Committee of the Department of Medicine, Ludwig Maximilians University Munich.

Provenance and peer review Not commissioned; externally peer reviewed.

Data sharing statement All data related to this study are published in this manuscript and in the related online supplementary information.

\section{REFERENCES}

1 Reinisch W, Sandborn WJ, Rutgeerts $P$, et al. Long-term infliximab maintenance therapy for ulcerative colitis: the ACT-1 and -2 extension studies. Inflamm Bowel Dis 2012:18:201-11.

2 Beigel F, Jurgens M, Filik L, et al. Severe Legionella pneumophila pneumonia following infliximab therapy in a patient with Crohn's disease. Inflamm Bowel Dis 2009; 15:1240-4.

3 Beigel $F$, Jurgens $M$, Tillack $C$, et al. Hepatosplenic T-cell lymphoma in a patient with Crohn's disease. Nat Rev Gastroenterol Hepatol 2009;6:433-6.

4 Rahier JF, Buche S, Peyrin-Biroulet L, et al. Severe skin lesions cause patients with inflammatory bowel disease to discontinue anti-tumor necrosis factor therapy. Clin Gastroenterol Hepatol 2010:8:1048-55.

5 Ko JM, Gottlieb AB, Kerbleski JF. Induction and exacerbation of psoriasis with TNF-blockade therapy: a review and analysis of 127 cases. J Dermatolog Treat 2009:20:100-8.

6 Cullen G, Kroshinsky D, Cheifetz AS, et al. Psoriasis associated with anti-tumour necrosis factor therapy in inflammatory bowel disease: a new series and a review of 120 cases from the literature. Aliment Pharmacol Ther 2011;34:1318-27.

7 Brand S. Crohn's disease: Th1, Th17 or both? The change of a paradigm: new immunological and genetic insights implicate Th17 cells in the pathogenesis of Crohn's disease. Gut 2009:58:1152-67.

8 Brand S, Beigel F, Olszak T, et al. IL-22 is increased in active Crohn's disease and promotes proinflammatory gene expression and intestinal epithelial cell migration. Am J Physiol Gastrointest Liver Physiol 2006;290:G827-38.

9 Schmechel S, Konrad A, Diegelmann J, et al. Linking genetic susceptibility to Crohn's disease with Th17 cell function: IL-22 serum levels are increased in Crohn's disease and correlate with disease activity and IL23R genotype status. Inflamm Bowel Dis 2008;14:204-12.

10 Dambacher J, Beigel F, Zitzmann K, et al. The role of the novel Th17 cytokine IL-26 in intestinal inflammation. Gut 2009:58:1207-17.

11 Seiderer J, Elben I, Diegelmann J, et al. Role of the novel Th17 cytokine IL-17F in inflammatory bowel disease (IBD): upregulated colonic IL-17F expression in active Crohn's disease and analysis of the IL17F p.His161Arg polymorphism in IBD. Inflamm Bowel Dis 2008;14:437-45.

12 Kryczek I, Bruce AT, Gudjonsson JE, et al. Induction of IL-17+ T cell trafficking and development by IFN-gamma: mechanism and pathological relevance in psoriasis. J Immunol 2008;181:4733-41.

13 Ma HL, Liang S, Li J, et al. IL-22 is required for Th17 cell-mediated pathology in a mouse model of psoriasis-like skin inflammation. J Clin Invest 2008;118:597-607.
14 Wolk K, Witte $E$, Wallace $E$, et al. IL-22 regulates the expression of genes responsible for antimicrobial defense, cellular differentiation, and mobility in keratinocytes: a potential role in psoriasis. Eur J Immunol 2006;36:1309-23.

15 Duerr RH, Taylor KD, Brant SR, et al. A genome-wide association study identifies IL23R as an inflammatory bowel disease gene. Science 2006:314:1461-3.

16 Glas J, Seiderer J, Wetzke M, et al. rs1004819 is the main disease-associated IL23R variant in German Crohn's disease patients: combined analysis of IL23R, CARD15, and OCTN1/2 variants. PLOS ONE 2007:2:e819.

17 Cargill M, Schrodi SJ, Chang M, et al. A large-scale genetic association study confirms IL12B and leads to the identification of IL23R as psoriasis-risk genes. Am J Hum Genet 2007:80:273-90.

18 Franke A, McGovern DP, Barrett JC, et al. Genome-wide meta-analysis increases to 71 the number of confirmed Crohn's disease susceptibility loci. Nat Genet 2010:42:1118-25.

19 Anderson CA, Boucher G, Lees CW, et al. Meta-analysis identifies 29 additional ulcerative colitis risk loci, increasing the number of confirmed associations to 47 . Nat Genet 2011:43:246-52.

20 Mannon PJ, Fuss IJ, Mayer L, et al. Anti-interleukin-12 antibody for active Crohn's disease. N Engl J Med 2004;351:2069-79.

21 Sandborn WJ, Feagan BG, Fedorak RN, et al. A randomized trial of ustekinumab, a human interleukin-12/23 monoclonal antibody, in patients with moderate-to-severe Crohn's disease. Gastroenterology 2008;135:1130-41.

22 Sandborn WJ, Gasink C, Gao LL, et al. A multicenter, randomized, double-blind, placebo-controlled phase $2 \mathrm{~b}$ study of ustekinumab, a human monoclonal antibody to IL-12/23p40, in patients with moderately to severely active Crohn's disease: results through week 22 from the Certifi trial. Gastroenterology 2011;140;S-109.

23 Sandborn WJ, Gasink C, Gao LL, et al. Ustekinumab induction and maintenance therapy in refractory Crohn's disease. N Engl J Med 2012;367:1519-28.

24 Lennard-Jones JE. Classification of inflammatory bowel disease. Scand J Gastroenterol Supp/ 1989;170:2-6; discussion 16-9.

25 Glas J, Seiderer J, Wagner J, et al. Analysis of IL12B gene variants in inflammatory bowel disease. PLOS ONE 2012;7:e34349.

26 Glas J, Seiderer J, Tillack C, et al. The NOD2 single nucleotide polymorphisms rs2066843 and rs2076756 are novel and common Crohn's disease susceptibility gene variants. PLOS ONE 2010;5:e14466.

27 Glas J, Seiderer J, Fries C, et al. CEACAM6 gene variants in inflammatory bowel disease. PLOS ONE 2011;6:e19319.

28 Glas J, Stallhofer J, Ripke S, et al. Novel genetic risk markers for ulcerative colitis in the IL2/IL21 region are in epistasis with IL23R and suggest a common genetic background for ulcerative colitis and celiac disease. Am J Gastroentero/ 2009; 104:1737-44

29 Seneschal J, Milpied B, Vergier B, et al. Cytokine imbalance with increased production of interferon-alpha in psoriasiform eruptions associated with antitumour necrosis factor-alpha treatments. Br J Dermatol 2009:161:1081-8.

30 Leonardi CL, Kimball AB, Papp KA, et al. Efficacy and safety of ustekinumab, a human interleukin-12/23 monoclonal antibody, in patients with psoriasis: 76-week results from a randomised, double-blind, placebo-controlled trial (PHOENIX 1). Lancet 2008:371:1665-74.

31 Papp KA, Langley RG, Lebwohl $M$, et al. Efficacy and safety of ustekinumab, a human interleukin-12/23 monoclonal antibody, in patients with psoriasis: 52-week results from a randomised, double-blind, placebo-controlled trial (PHOENIX 2). Lancet 2008;371:1675-84.

32 Griffiths $C E$, Strober BE, van de Kerkhof $P$, et al. Comparison of ustekinumab and etanercept for moderate-to-severe psoriasis. N Engl J Med 2010;362:118-28.

33 Nair RP, Duffin KC, Helms $C$, et al. Genome-wide scan reveals association of psoriasis with IL-23 and NF-kappaB pathways. Nat Genet 2009;41:199-204.

34 Liu Y, Helms C, Liao W, et al. A genome-wide association study of psoriasis and psoriatic arthritis identifies new disease loci. PLoS Genet 2008;4:e1000041.

35 Zhang XJ, Huang W, Yang $\mathrm{S}$, et al. Psoriasis genome-wide association study identifies susceptibility variants within LCE gene cluster at 1q21. Nat Genet 2009;41:205-10.

36 Sarin R, Wu X, Abraham C. Inflammatory disease protective R381Q IL23 receptor polymorphism results in decreased primary CD4+ and CD8+ human T-cell functional responses. Proc Natl Acad Sci USA 2011;108:9560-5.

37 Di Meglio P, Di Cesare A, Laggner U, et al. The IL23R R381Q gene variant protects against immune-mediated diseases by impairing IL-23-induced Th17 effector response in humans. PLOS ONE 2011:6:e17160.

38 Pidasheva S, Trifari S, Phillips A, et al. Functional studies on the IBD susceptibility gene IL23R implicate reduced receptor function in the protective genetic variant R381Q. PLOS ONE 2011;6:e25038.

39 Liang SC, Tan XY, Luxenberg DP, et al. Interleukin (IL)-22 and IL-17 are coexpressed by Th17 cells and cooperatively enhance expression of antimicrobial peptides. J Exp Med 2006;203:2271-9.

40 Nestle FO, Kaplan DH, Barker J. Psoriasis. N Engl J Med 2009;361:496-509.

41 Flendrie M, Vissers WH, Creemers MC, et al. Dermatological conditions during TNF-alpha-blocking therapy in patients with rheumatoid arthritis: a prospective study. Arthritis Res Ther 2005;7:R666-76.

42 Lee $\mathrm{HH}$, Song $\mathrm{IH}$, Friedrich $\mathrm{M}$, et al. Cutaneous side-effects in patients with rheumatic diseases during application of tumour necrosis factor-alpha antagonists. Br J Dermatol 2007:156:486-91. 
43 Shmidt E, Wetter DA, Ferguson SB, et al. Psoriasis and palmoplantar pustulosis associated with tumor necrosis factor-alpha inhibitors: the Mayo Clinic experience, 1998 to 2010. J Am Acad Dermatol 2012;67:e179-85.

44 Iborra M, Beltran B, Bastida G, et al. Infliximab and adalimumab-induced psoriasis in Crohn's disease: a paradoxical side effect. J Crohns Colitis 2011:5:157-61.

45 Guerra I, Algaba A, Perez-Calle JL, et al. Induction of psoriasis with anti-TNF agents in patients with inflammatory bowel disease: a report of 21 cases. J Crohns Colitis 2012;6:518-23.

46 Buisson A, Cuny JF, Barbaud A, et al. Methotrexate for psoriasiform lesions associated with anti-tumour necrosis factor therapy in inflammatory bowel disease. Aliment Pharmacol Ther 2012;35:1175-80.

47 Cleynen I, Vermeire S. Paradoxical inflammation induced by anti-TNF agents in patients with IBD. Nat Rev Gastroenterol Hepatol 2012;9:496-503.

48 Harrison MJ, Dixon WG, Watson KD, et al. Rates of new-onset psoriasis in patients with rheumatoid arthritis receiving anti-tumour necrosis factor alpha therapy: results from the British Society for Rheumatology Biologics Register. Ann Rheum Dis 2009:68:209-15.

49 Naldi L, Chatenoud L, Linder D, et al. Cigarette smoking, body mass index, and stressful life events as risk factors for psoriasis: results from an Italian case-control study. I Invest Dermatol 2005;125:61-7.

50 Manni E, Barachini P. Psoriasis induced by infliximab in a patient suffering from Crohn's disease. Int I Immunopathol Pharmacol 2009;22:841-4.

51 Yu RY, Gallagher G. A naturally occurring, soluble antagonist of human IL-23 inhibits the development and in vitro function of human Th17 cells. I Immunol 2010:185:7302-8.

52 Sherlock ME, Walters T, Tabbers MM, et al. Infliximab-induced psoriasis and psoriasiform skin lesions in pediatric Crohn's disease and a potential association with IL-23 receptor polymorphisms. J Pediatr Gastroenterol Nutr 2013;56: 512-8.

53 Palucka AK, Blanck JP, Bennett $L$, et al. Cross-regulation of TNF and IFN-alpha in autoimmune diseases. Proc Natl Acad Sci USA 2005;102:3372-7.

54 Wollenberg A, Wagner M, Gunther $S$, et al. Plasmacytoid dendritic cells: a new cutaneous dendritic cell subset with distinct role in inflammatory skin diseases. J Invest Dermatol 2002:119:1096-102.
55 de Gannes GC, Ghoreishi M, Pope J, et al. Psoriasis and pustular dermatitis triggered by TNF-\{alpha\} inhibitors in patients with rheumatologic conditions. Arch Dermatol 2007:143:223-31.

56 Schroepf S, Kappler R, Brand S, et al. Strong overexpression of CXCR3 axis components in childhood inflammatory bowel disease. Inflamm Bowel Dis 16:1882-90

57 Teunissen MB, Koomen CW, de Waal Malefyt R, et al. Interleukin-17 and interferon-gamma synergize in the enhancement of proinflammatory cytokine production by human keratinocytes. I Invest Dermatol 1998;111: 645-9.

58 Leonardi C, Matheson R, Zachariae C, et al. Anti-interleukin-17 monoclonal antibody ixekizumab in chronic plaque psoriasis. N Engl J Med 2012;366: $1190-9$.

59 Papp KA, Leonardi C, Menter A, et al. Brodalumab, an anti-interleukin-17-receptor antibody for psoriasis. N Engl J Med 2012;366:1181-9.

60 Wolk K, Haugen HS, Xu W, et al. IL-22 and IL-20 are key mediators of the epidermal alterations in psoriasis while IL-17 and IFN-gamma are not. J Mol Med 2009;87:523-36

61 Boniface K, Bernard FX, Garcia M, et al. IL-22 inhibits epidermal differentiation and induces proinflammatory gene expression and migration of human keratinocytes. J Immunol 2005;174:3695-702.

62 http://www.clinicaltrials.gov/show/NCT00563524 (accessed 1 Oct 2012).

63 Nickoloff BJ, Nestle FO. Recent insights into the immunopathogenesis of psoriasis provide new therapeutic opportunities. I Clin Invest 2004;113:1664-75.

64 Zheng Y, Danilenko DM, Valdez P, et al. Interleukin-22, a T(H)17 cytokine, mediates IL-23-induced dermal inflammation and acanthosis. Nature 2007:445:648-51.

65 Downs AM, Dunnill MG. Exacerbation of psoriasis by interferon-alpha therapy for hepatitis C. Clin Exp Dermatol 2000;25:351-2.

66 Niess JH, Leithauser $F$, Adler $G$, et al. Commensal gut flora drives the expansion of proinflammatory CD4T cells in the colonic lamina propria under normal and inflammatory conditions. J Immunol 2008:180:559-68.

67 Ramgolam VS, Sha Y, Jin J, et al. IFN-beta inhibits human Th17 cell differentiation. J Immunol 2009:183:5418-27. 


\section{GUT}

Anti-TNF antibody-induced psoriasiform skin lesions in patients with inflammatory bowel disease are characterised by interferon- $\gamma$ -expressing Th1 cells and IL-17A/IL-22-expressing Th17 cells and respond to anti-IL-12/IL-23 antibody treatment

Cornelia Tillack, Laura Maximiliane Ehmann, Matthias Friedrich, Rüdiger P Laubender, Pavol Papay, Harald Vogelsang, Johannes Stallhofer, Florian Beigel, Andrea Bedynek, Martin Wetzke, Harald Maier, Maria Koburger, Johanna Wagner, Jürgen Glas, Julia Diegelmann, Sarah Koglin, Yvonne Dombrowski, Jürgen Schauber, Andreas Wollenberg and Stephan Brand

Gut 2014 63: 567-577 originally published online March 6, 2013 doi: 10.1136/gutjnl-2012-302853

Updated information and services can be found at:

http://gut.bmj.com/content/63/4/567

These include:

Supplementary Material

References

Email alerting service
Supplementary material can be found at:

http://gut.bmj.com/content/suppl/2013/03/04/gutjnl-2012-302853.DC1

This article cites 64 articles, 15 of which you can access for free at: http://gut.bmj.com/content/63/4/567\#BIBL

Receive free email alerts when new articles cite this article. Sign up in the box at the top right corner of the online article.

Topic Articles on similar topics can be found in the following collections

Collections

Crohn's disease (932)

\section{Notes}

To request permissions go to:

http://group.bmj.com/group/rights-licensing/permissions

To order reprints go to:

http://journals.bmj.com/cgi/reprintform

To subscribe to BMJ go to:

http://group.bmj.com/subscribe/ 